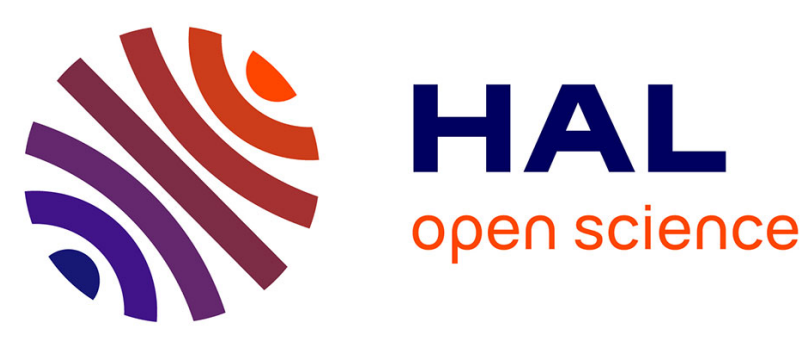

\title{
Ground Penetrating Radar Two-Way Travel Time Sensitivity to Hydrodynamic Parameters During Soil Water Infiltration
}

Rohianuu Moua, Jean-François Girard, N. Lesparre, Benjamin Belfort, Francois Lehmann, Anis Younes

\section{To cite this version:}

Rohianuu Moua, Jean-François Girard, N. Lesparre, Benjamin Belfort, Francois Lehmann, et al.. Ground Penetrating Radar Two-Way Travel Time Sensitivity to Hydrodynamic Parameters During Soil Water Infiltration. European Association of Geoscientists \& Engineers, Aug 2021, Bordeaux, France. hal-03426864

\section{HAL Id: hal-03426864 https://hal.science/hal-03426864}

Submitted on 12 Nov 2021

HAL is a multi-disciplinary open access archive for the deposit and dissemination of scientific research documents, whether they are published or not. The documents may come from teaching and research institutions in France or abroad, or from public or private research centers.
L'archive ouverte pluridisciplinaire HAL, est destinée au dépôt et à la diffusion de documents scientifiques de niveau recherche, publiés ou non, émanant des établissements d'enseignement et de recherche français ou étrangers, des laboratoires publics ou privés. 


\title{
( NEAR SURFaCE - GEOSCIENCE'?
}

\section{Ground penetrating radar two-way travel time sensitivity to the hydrodynamic parameters during soil water infiltration}

\author{
R. Moua ${ }^{1}$, J. Girard ${ }^{1}$, N. Lesparre ${ }^{1}$, B. Belfort ${ }^{1}$, F. Lehmann ${ }^{1}$ and A. Younes ${ }^{1}$ \\ 1) Université de Strasbourg, CNRS, ENGEES, EOST, ITES UMR7063, F-67000 Strasbourg, \\ France
}

\section{Introduction}

Soil water content variation experiments such as imbibition, drainage or infiltration were carried out on both controlled and natural sites and monitored using in-situ devices and geophysical measurements, namely ground penetrating radar (GPR), magnetic resonance sounding and self-potential.

In this study we consider the case of soil water infiltration experiments monitored with time-lapse GPR for which a coupled hydrogeological-geophysical model has been established. The final objective is to develop a fitting methodology of the hydrodynamic parameters of the model so that it provides a correct reproduction of the GPR data observed in real conditions.

In a first part presented here, we focus on how the synthetic two-way travel times for the wetting front and for reflectors of fixed depths, are sensitive to the hydrodynamic parameters of a homogeneous soil. To this end, global sensitivity analysis (GSA) has been performed to characterize the influence of the hydrodynamic parameters on the variations of the two-way travel times.

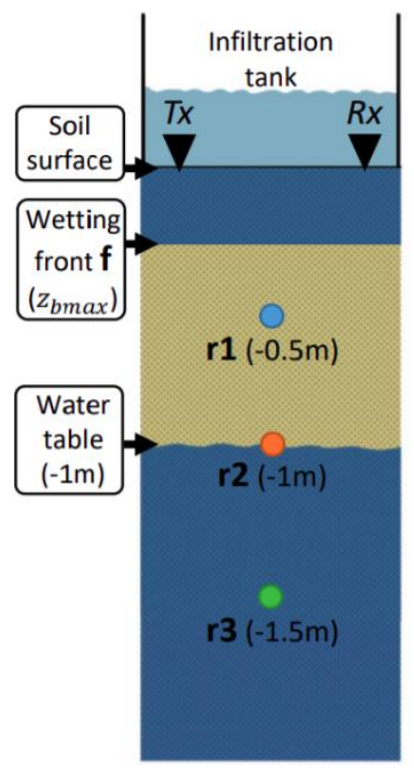

Figure 1 Illustration of the modelled infiltration experiment. $r 1, r 2$ and r3 are reflectors at fixed depths.

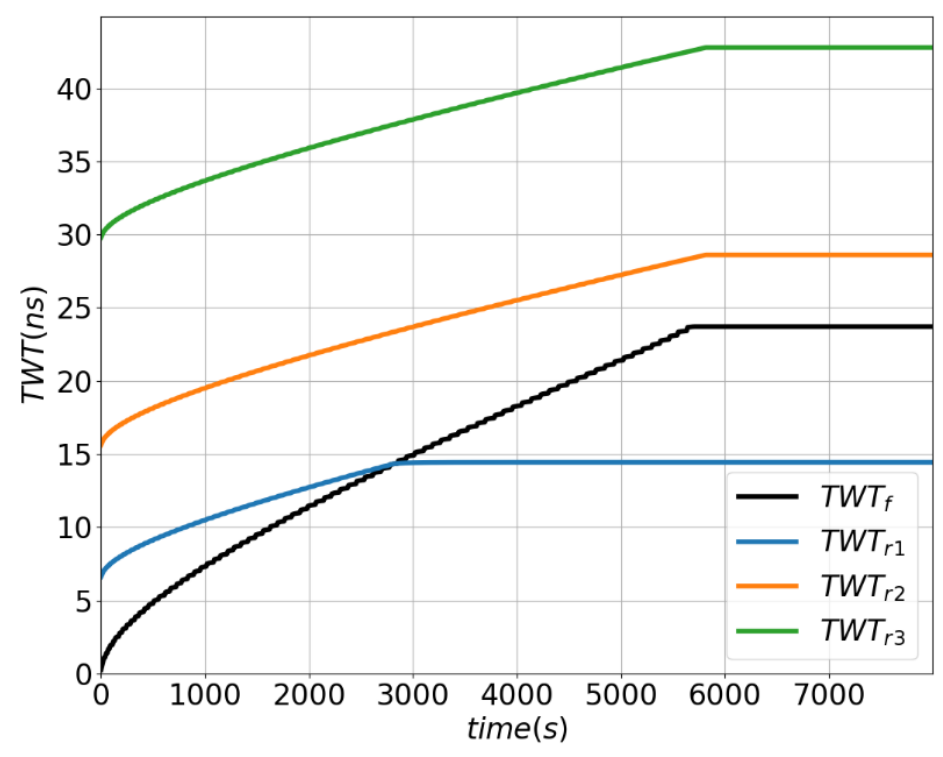

Figure 2 Synthetic outputs for a given set of input hydrodynamic parameters, depicting the two-way travel times for the wetting front $f$ and the fixed reflectors $r 1, r 2$ and $r 3$.

\section{Methods}

Soil water infiltration experiment consists in applying a water charge, potentially inside an infiltration tank, on the soil surface. Here we considered a $10 \mathrm{~cm}$ constant head infiltration with a total duration of 8000 s and a water table level set and maintained at $1 \mathrm{~m}$ deep from the soil surface.

The hydrogeological model uses the WAMOS-1D code (Belfort et al. 2018) which combines the Richards equation in 1D with the Mualem - van Genuchten (MvG) model to describe the constitutive relationships between the pressure, the hydraulic conductivity and the water content. The head applied 


\section{CONFERENCE \& EXHIBITION NEAR SURFACE - GEOSCIENGE"}

in the infiltration tank and the water table level are respectively set as the top and the bottom boundary conditions. The porous medium is initially considered at the hydrostatic equilibrium. For a given set of MvG hydrodynamic parameters $X=\left(K_{s}, \theta_{r}, \theta_{s}, \alpha, n\right)$, the code solves the hydrogeological model and yields the vertical water content profile over time $\theta(z, t)$.

In our geophysical modeling code, the $\theta(z, t)$ profile is converted, through a series of equations (for instance, see Leger et al. 2014), into two-way travel time $T W T\left(z_{b}, t\right)$ and reflection coefficient $r\left(z_{b}, t\right)$ profiles, evaluated at each mid-point between two cells of the 1D domain. The two-way travel times of reflections occurring at fixed depths are directly obtained with the $T W T\left(z_{b}, t\right)$ profile. Introducing three heterogeneities $\mathrm{r} 1, \mathrm{r} 2$ and $\mathrm{r} 3$ at respective depths of $0.5 \mathrm{~m}, 1 \mathrm{~m}$ and $1.5 \mathrm{~m}$, as illustrated in figure 1 , we can follow the evolution of $T W T_{r 1}, T W T_{r 2}$ and $T W T_{r 3}$ over time. In a homogeneous soil, the wetting front is a strong reflector, accounted for the maximum of the reflection coefficient profile. Hence, the related two-way travel time $T W T_{f}$ can be derived at each time step from $T W T\left(z_{b \max }, t\right)$ with $z_{\text {bmax }}=$ $\left\{z_{b} \mid r\left(z_{b \max }\right)=\max (r)\right\}$. For a given $X$, the GPR modeling code generates an output set $Y(X)=$ $\left(T W T_{f}, T W T_{r 1}, T W T_{r 2}, T W T_{r 3}\right)$ as seen in figure 2.

Among the various forms of GSA, a variance-based sensitivity analysis relying on the calculation of Sobol indices has been performed, which allows to quantify the contribution of the variation of any input variable $x \in X$, to the total variance of an output variable $y \in Y$. A practical approach to save computational time is to conduct surrogate modeling based on the Polynomial Chaos Expansion (PCE) method, which consists in developing an output $y \in Y$ as a set of multivariate polynomials (Younes et al. 2018). The related polynomial coefficients can be estimated in the least square sense using a large number $(M)$ of random realizations of the forward hydro-geophysical model, and the Sobol indices can be directly calculated from these coefficients. The whole process is illustrated in figure 3.

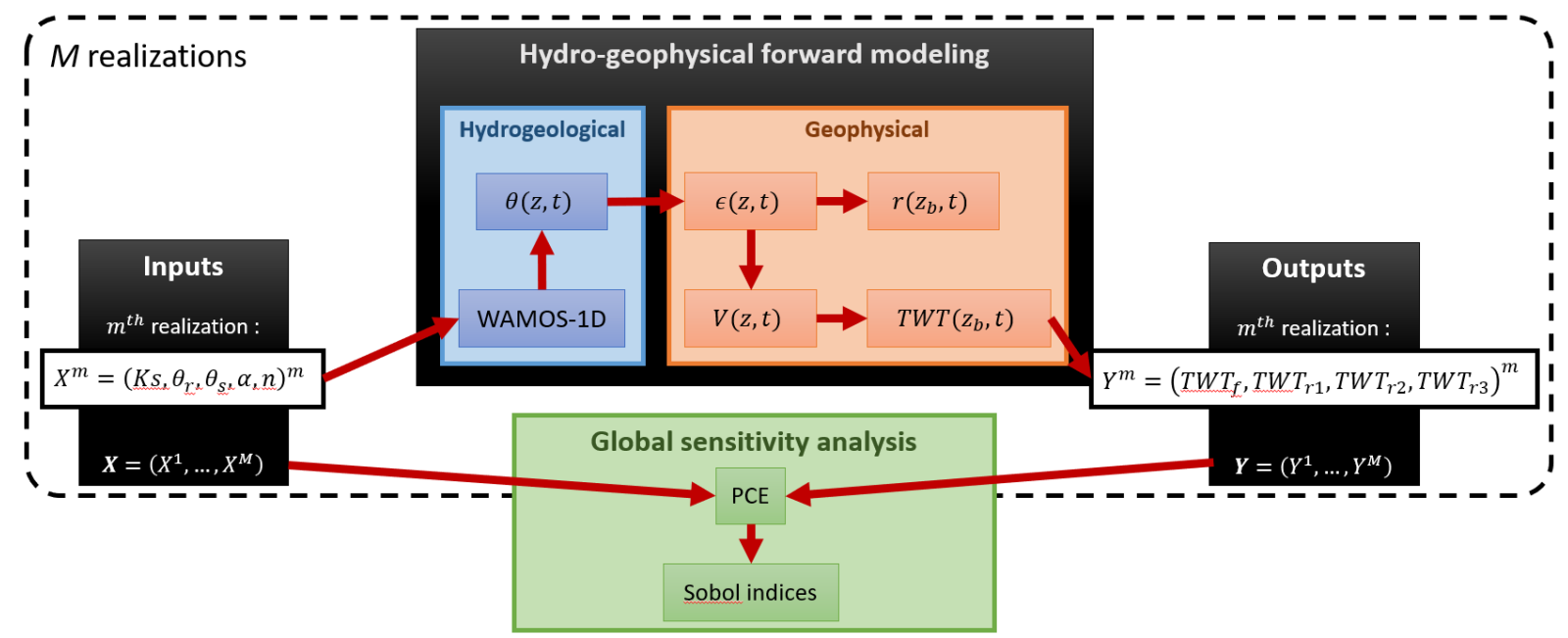

Figure 3 Methodology of the GSA applied on the hydro-geophysical model.

\section{Results \& Discussion}

We ran $M=1258$ realizations of the hydro-geophysical model where each input variable $x \in X$ is randomly sampled from a uniform distribution. The first order Sobol indices of each input parameter, that is their contribution to the total variance when considered separately, are shown in figure 4 and their total Sobol indices, hence also including higher order contributions, are shown in figure 5.

Regarding the results in figure 4, overall, the variance evolves during the infiltration through a short increasing phase I and a longer decreasing phase II. A first comparison between all outputs shows that $T W T_{f}$ generates the largest total variance. For $T W T_{f}, K_{s}$ remains the only influential parameter during phase I, while $\alpha$ earns influence with time in phase II. The three other parameters have little to no effect. For $T W T_{r 1}, \alpha$ is the most influential parameter at the very beginning of the infiltration but with a 


\section{Demmannmm NEAR SURFACE GEOSCIENCE'21}

decreasing importance with time. Very quickly, $K_{S}$ contribution increases and exceeds the importance of $\alpha$ during phase I; its contribution decreases to zero during phase II. Compared to what is observed for $T W T_{f}, \theta_{s}$ has a relatively more important contribution, remaining the only influential parameter at the end of the infiltration, but with a smaller total variance. $T W T_{r 2}$ and $T W T_{r 3}$ depict a similar behavior than $T W T_{r 1}$. Notice that the total variance and $\theta_{s}$ contribution are more important for $T W T_{r 2}$ and even more for $T W T_{r 3}$. The influence of $\theta_{s}$ increases with the depth of the object under the water table, which can be related to the increasing length of the saturated travel path. Another observation common to all outputs is the presence of interactions between input parameters contributions, as evidenced by the blank part between the filled curves and the total variance curve. An input parameter not influential alone can have an effect when varying with one or more other input parameters. Given the results depicted in figure 5, these interactions are also explained by $K_{s}$ and $\alpha$ for $T W T_{f}$ and by $K_{s}, \alpha$ and $\theta_{S}$ for $T W T_{r 1}, T W T_{r 2}$ and $T W T_{r 3}$.

\section{Conclusion \& Perspectives}

Time-lapse GPR is a useful non-invasive solution to monitor soil water infiltration experiments. We developed a coupled hydrogeological and geophysical model and performed a global sensitivity analysis based on Sobol indices. Considering the two-way travel times for the wetting front and for fixed reflectors, we have shown how complementary those two types of GPR data can be and we have evidenced the main contribution of the soil input hydrodynamic parameters $K_{s}, \alpha$ and $\theta_{s}$ on the total variance of these data. Indeed, the two-way travel times of reflected waves on objects of fixed depths appear to be more sensitive to $\theta_{s}$ at long times than the two-way travel times of the wetting front,
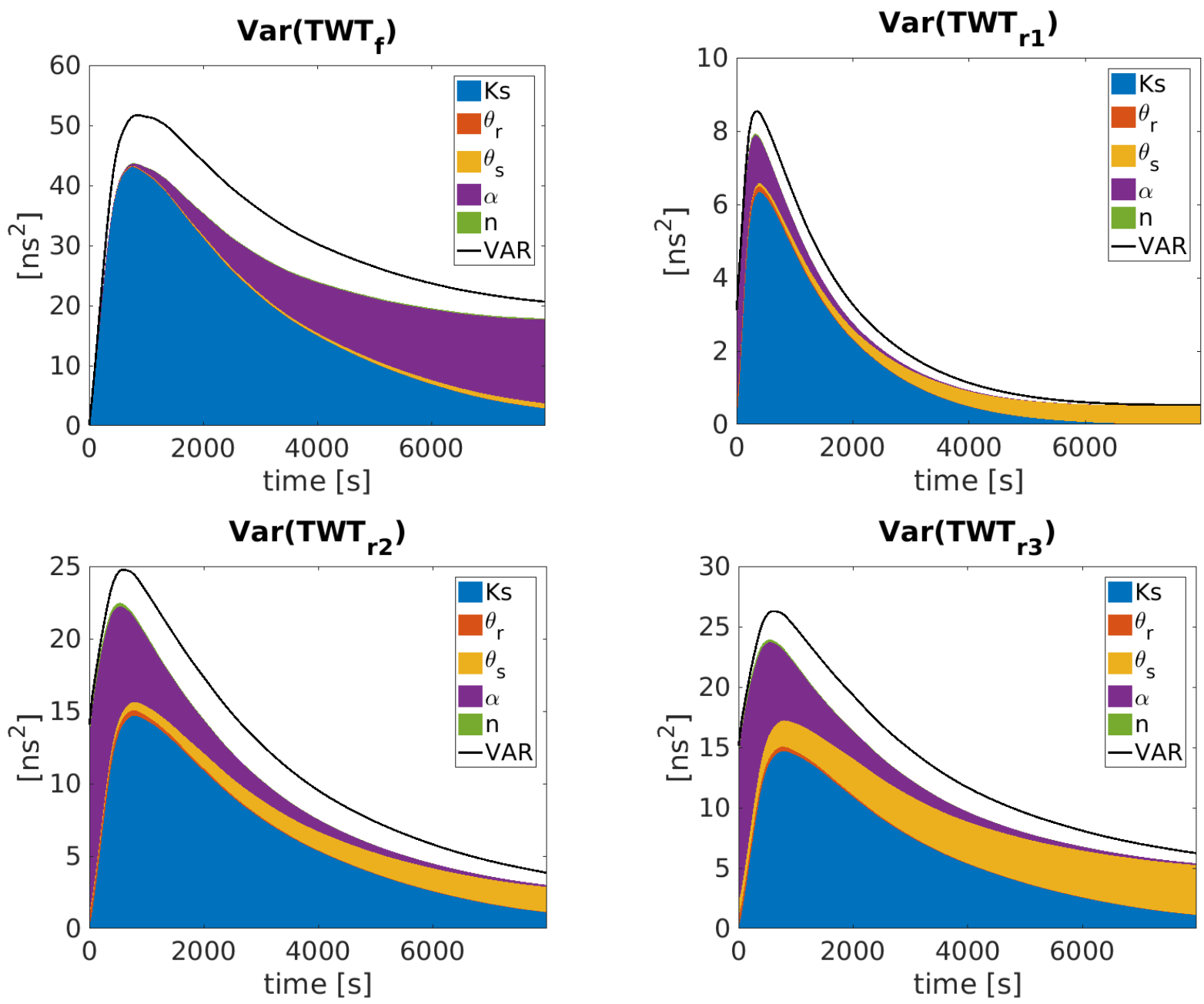

Figure 4 Results of the GSA for each output $\boldsymbol{y}(\boldsymbol{X}) \in \boldsymbol{Y}(\boldsymbol{X})=\left(\boldsymbol{T} \boldsymbol{W} \boldsymbol{T}_{f}, \boldsymbol{T W} \boldsymbol{T}_{r 1}, \boldsymbol{T W} \boldsymbol{T}_{r 2}, \boldsymbol{T W} \boldsymbol{T}_{r 3}\right)$. The coloured areas represent the first order Sobol indices, the part of the total variance explained by each input parameter $\boldsymbol{x} \in \boldsymbol{X}=\left(\boldsymbol{K}_{\boldsymbol{s}}, \boldsymbol{\theta}_{\boldsymbol{r}}, \boldsymbol{\theta}_{\boldsymbol{s}}, \boldsymbol{\alpha}, \boldsymbol{n}\right)$ multiplied by the total variance, over time. 


\section{. MEAR SURFACE - GEOSCIENGE'?}

particularly when the depth of the object under the water table level increases. We assume this to be due to an increasing length of the travel path in the saturated zone. Upcoming runs will be performed on soil models with deeper water table level to cover the case of undetectable water table. The second part of this work will consider the inversion algorithm to determine the optimal settings for field measurements and apply the methodology on real data acquired in various contexts.
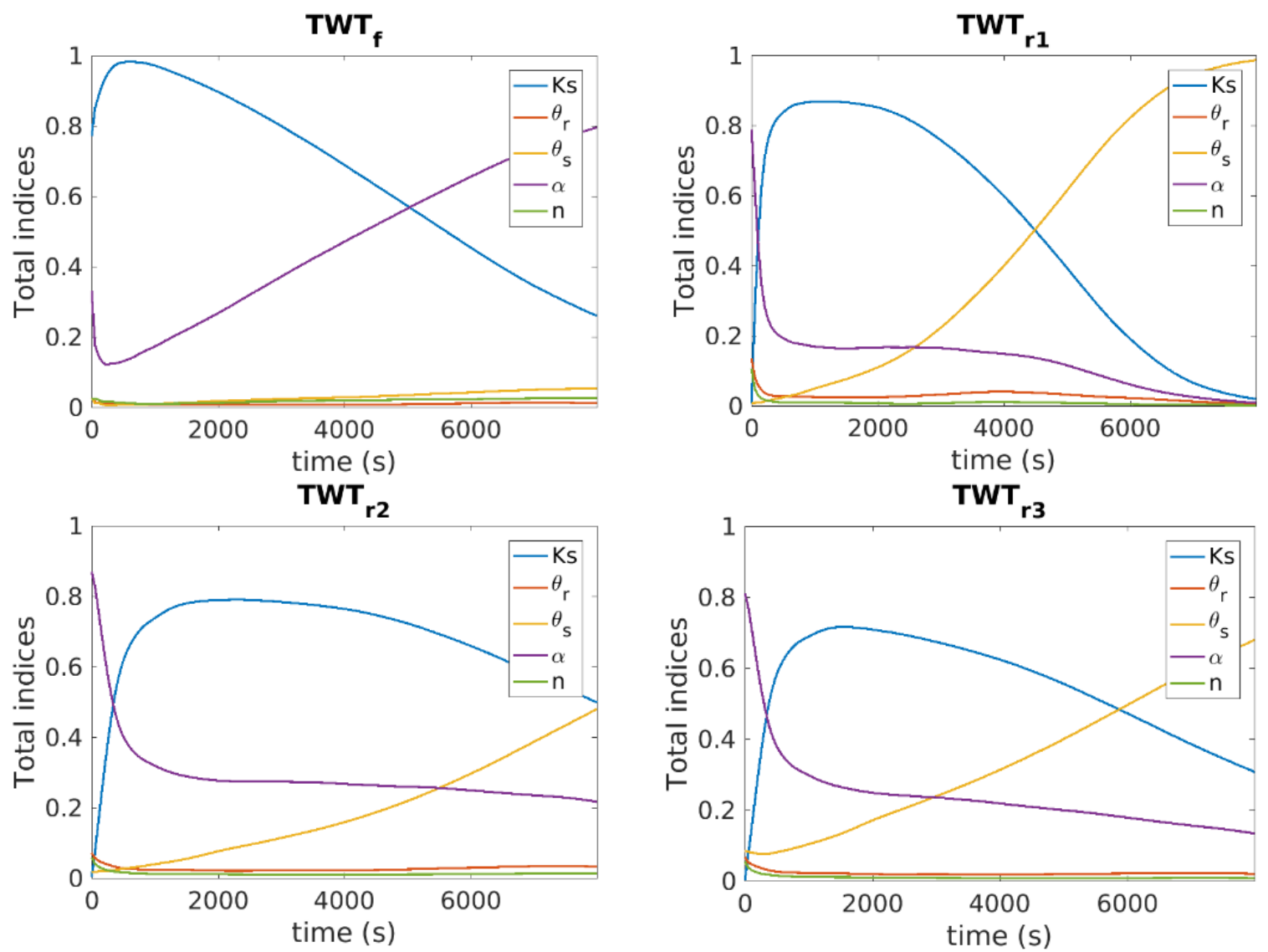

Figure 5 Results of the GSA for each output $\boldsymbol{y}(\boldsymbol{X}) \in \boldsymbol{Y}(\boldsymbol{X})=\left(\boldsymbol{T} \boldsymbol{W} \boldsymbol{T}_{f}, \boldsymbol{T} \boldsymbol{W} \boldsymbol{T}_{r 1}, \boldsymbol{T W} \boldsymbol{T}_{r 2}, \boldsymbol{T} \boldsymbol{W} \boldsymbol{T}_{r 3}\right)$ : total Sobol indices of each input parameter $\boldsymbol{x} \in \boldsymbol{X}$, including all interactions of $x$ with every other parameter.

\section{Acknowledgements}

The doctoral position of the first author is co-funded by the Grand-Est Region and the University of Strasbourg. This research work is partly funded by the French National Research Agency through the Exciting project $n^{\circ}$ ANR-17-CE06-0012-01.

\section{References}

Belfort, B., Toloni, I., Ackerer, P., Cotel, S., Viville,D. and Lehmann, F. [2018] Vadose Zone Modeling in a Small Forested Catchment: Impact of Water Pressure Head Sampling Frequency on 1D-Model Calibration. Geosciences, 8(2), 72.

Leger, E., Saintenoy, A. and Coquet, Y. [2014] Hydrodynamic parameters of a sandy soil determined by ground-penetrating radar inside a single ring infiltrometer. Water Resources Research, 50, 54595474.

Younes, A., Zaouali, J., Lehmann, F. and Fahs, M. [2018] Sensitivity and identifiability of hydraulic and geophysical parameters from streaming potential signals in unsaturated porous media. Hydrology and Earth System Sciences, 22, 3561-3574. 